\title{
FREGE'S CONCEPTION OF TRUTH: Two READINGS
}

\author{
JUNYEOL KIM \\ University of Connecticut
}

\begin{abstract}
The object reading of Frege's conception of truth holds that, for him, truth is an object-the truth-value the True. Greimann refutes the object reading and suggests an alternative reading. According to his suggested reading, Frege is a proponent of the assertion theory of truth, the main thesis of which is that truth is what is expressed by the form of assertoric sentences, and truth as such is neither an object nor a property. I argue that Frege cannot accept the assertion theory. I also defend the object reading by elaborating it further and replying to Greimann's criticisms.
\end{abstract}

\section{Frege's Conception of Truth: An Object or a Property?}

It is widely accepted by commentators that, for Frege, truth is not a property of thoughts (Burge 1986; Carruthers 1981; Dummett 1973; Heck 2007; 2012; Kremer 2000; Pagin 2001; Ricketts 1996: 2007). In 'On Sense and Reference', Frege maintains that the reference of a sentence is a truth-value: the True or the False. On the True, he writes,

One might be tempted to regard the relation of the thought to the True ... rather as that of subject to predicate. One can, indeed, say: 'The thought, that 5 is a prime number, is true'. But closer examination shows that nothing more has been said than in the simple sentence ' 5 is a prime number'.... It follows that the relation of the thought to the True may not be compared with that of subject to predicate. $(1892 \mathrm{C}: 64)^{1}$

Contact: Junyeol Kim <junyeol.kim@uconn.edu>

1. Citing Frege's works, I specify the year of publication of the work if it is published or the conjectured year of completion if it is originally unpublished. The year of the cited work is followed by the page number of its translation. The translation of the cited work is displayed in the bibliography. For the translation of articles, I mostly depend on Frege (1970), (1979) and 
Frege's argument in this passage can be reconstructed as follows. Say that 'true' in 'The thought that 5 is a prime number is true' denotes the True. Provided that 'true' is a predicate and hence denotes a property of thoughts, then the thought $\langle 5$ is a prime number $\rangle$ should be different from $\langle\langle 5$ is a prime number $\rangle$ is true $\rangle.{ }^{2}$ However, they are identical. Therefore, the True cannot be a property. This argument shows that what we attempt to express by 'true', that is, truth, cannot be a property of thoughts for Frege.

Then what is truth for Frege? The argument also adumbrates Frege's answer to this question. The conclusion of the argument, that the relation of a thought to the True is not that of subject to predicate, follows only if 'true' is considered as denoting the True. ${ }^{3}$ This appears to support the claim that Frege identifies truth with the True, which he clearly takes to be an object. Thus, the standard reading maintains that truth is an object for him. ${ }^{4}$ We may call this standard reading 'the object reading'.

However, Greimann (2004; 2007) holds that the object reading does not square well with textual evidence. His first argument is that 'Thought' (Frege 1918a), in which Frege mainly talks about truth, 'is not concerned with determining the logical category of the truth-values; rather, the truth-values are not mentioned at all' (Greimann 2004 438). This seems to show that Frege's conception of truth is not related to the True. Greimann's second argument (2004; 438; 2007; 141-142) concerns the peculiarity of truth Frege points out. In 'Thought', Frege remarks,

We cannot recognize a property of a thing without at the same time finding the thought this thing has this property to be true. So with every property of a thing there is tied up a property of a thought, namely truth. (1918a 328)

This conflicts with the passage from 'On Sense and Reference'. However, Greimann thinks that Frege is revealing a part of his conception of truth, which is that 'predicating truth is always included in predicating anything whatever' Greimann 2004: 438) though truth is not a property. But the True cannot be predicated.

Greimann's third argument against the object reading concerns the indefinability of truth. Frege (1897; 1918a) famously maintains that truth is indefinable. The problem is that the True seems to be definable. Greimann points out that, 'in order to overcome the referential indeterminacy of value-[range] terms in his system, Frege identifies in $\S 10$ of Grundgesetze with the value-[range] of the

1997).

2. ' $\langle p\rangle$ ' means 'the thought that $p^{\prime}$.

3. The same kind of connection between the True and truth is made in 'Introduction to Logic' 1906a 194).

4. Almost all commentators who accept that truth is not a property for Frege also accept that truth is an object for him. For the examination of this reading, see Burge (1986), Heck 2007, 2012), Ricketts (1996, 2007). 
function $-x^{\prime}$ (Greimann 2007 142). ${ }^{5}$ Greimann interprets this fact as showing that Frege defines the True as follows: The True $=\dot{\epsilon}(-\epsilon)$. If so, the True which is definable cannot be truth.

If this critique is correct and truth cannot be an object for Frege, we are lost in regards to his conception of truth. If truth is neither a property nor an object, what is it then?

Greimann presents an alternative reading. In this reading, the details of which I introduce in the next section, Frege's conception of truth consists in the assertion theory of truth (Greimann 2007), the main claim of which is that truth is expressed by the form of assertoric sentences and truth as such is neither a property nor an object. If we fully understand the assertion theory of truth, Frege's remarks on truth we have seen are not puzzling anymore. Or so argues Greimann.

I call this alternative 'the A-theory reading'. My first aim is to show that Frege cannot accept the main claims of the assertion theory. If my argument is correct, the A-theory reading should be discarded. My second aim is to defend the object reading through elaborating it further and replying to Greimann's criticisms. If my defense is along the right lines, then the object reading is still a viable interpretation of Frege's conception of truth.

Section 2 explains the A-theory reading. Section 3 is my critique of the reading. Section 4 is the elaboration and defense of the object reading.

\section{The A-Theory Reading of Frege's Conception of Truth}

The A-theory reading (Greimann 2004; 2007; 2014) starts with pointing out that Frege's primary question regarding truth is what kind of role the notion of truth plays in judging and asserting. The gist of the A-theory reading is that Frege's answer to this question develops into the assertion theory of truth.

According to Frege, judging that $p$ is acknowledging the truth of $\langle p\rangle$. Asserting is judging externally manifested. ${ }^{6}$ The question as to what role truth plays in judging and asserting then comes down to that as to how we acknowledge the truth of a thought. One possible answer is that we do so by predicating the property truth of a thought. This answer is not available for Frege because he gainsays that truth is a property. However, Frege has an independent reason to deny the answer. This reason is relevant to our discussion.

For Frege, predicating a property $P x$ of an object $o$ is nothing more than grasping $\langle P o\rangle$.

By combining subject and predicate, one reaches only a thought.... (Frege

5. I use 'value-range' instead of 'value-course' following Ebert and Rossberg's translation (Frege 2013) of Grundgesetze.

6. See 'Thought' (Frege 1918a 329).

Ergo • vol. 6, no. 2 2019 
1892C: 64$)^{7}$

By predicating the property death of Caesar, all we achieve is to grasp /Caesar is dead $\rangle.{ }^{8}$ Grasping this thought falls short of acknowledging its truth. ${ }^{9}$ An actor on stage who utters the sentence 'Caesar is dead' would grasp 〈Caesar is dead $\rangle$. But the actor would not thereby acknowledge its truth. Though grasping a thought is necessary for acknowledging its truth, it is not sufficient.

Predicating is confused with judging. ... Once we have grasped a thought, we can recognize it as true [i.e., acknowledge its truth]. (Frege 1906a: 185) ${ }^{10}$

In this view of predication, all one can achieve by predicating the property truth of $\langle p\rangle$ is just to grasp $\langle\langle p\rangle$ is true $\rangle$. But one cannot acknowledge the truth of $\langle\langle p\rangle$ is true $\rangle$ or $\langle p\rangle$ by grasping $\langle\langle p\rangle$ is true $\rangle$. For Frege, acknowledging the truth of a thought cannot be merely predicating the property truth of the thought even if there were such a property.

The lesson is that one should do more than grasp $\langle p\rangle$ to acknowledge its truth, that is, to judge that $p$. According to the A-theory reading (Greimann 2004: 435-436; 2007. 136), this additional component of judging can be found in Frege's mature version of Begriffsschrift (1893). Let ' $\Phi$ ' be a proper term of the mature Begriffsschrift. In the mature Begriffsschrift, writing down

\section{$\Phi$}

is equivalent to judging that $\Phi$. The horizontal line is called 'the horizontal' and the vertical stroke is called the judgment stroke'. ${ }^{11}$ What we need to note is the role of the judgment stroke in ' $\mid \Phi$ '. Frege comments in 'Function and Concept':

7. Frege $[$ 1892a) points out that predicating a property $P x$ of an object $o$ is merely one type of combining subject and predicate. Saying that all rabbits are mammals is combining subject and predicate, but not predicating a property of an object. For this reason, Frege argues that the subject-predicate analysis of logical form is defective and hence should be abandoned.

8. Predicating a property of an object is an act of predication in the level of reference. What Frege means by the phrase 'combining subject and predicate' above is exactly this type of predication. See Frege (1892a).

9. Grasping a thought is necessary for taking a propositional attitude toward the thought. To assume, desire, or assert that $p$, one should first grasp $\langle p\rangle$. This means that grasping a thought itself is not taking a propositional attitude toward the thought. For this point, see Textor (2010).

10. Künne 2013) provides an excellent discussion about the distinction between grasping a thought and acknowledging its truth in Frege. Also see Greimann (2004) and (2008).

11. We do not deal with the horizontal in this paper. However, it is still an unsolved issue why Frege makes the horizontal an indispensable part of Begriffsschriftsatz, i.e., well-formed Begriffsschrift sentences. For the examination of this issue, see Heck and Lycan (1979) and Taschek 2008). 
We thus need a special sign in order to be able to assert something. To this end I make use of a vertical stroke at the left end of the horizontal, so that, e.g. by writing

$$
\vdash 2+3=5
$$

We assert that $2+3$ equals 5 . Thus here we are not just writing down a truth-value, as in

$$
2+3=5,
$$

but also at the same time saying that it is the True. (Frege 1891; 34)

In Frege's framework, sentences like 'The sum of 2 and 3 is equal to 5 ' are names of truth-values. To say ' $2+3=5$ is (identical with) the True' is fine, though it is an ungrammatical sentence in ordinary English. Frege here seems to be arguing that

$\left(A_{1}\right)$ We express the claim that $\Phi$ is the True by putting ' $F$ ' in front of ' $\Phi$ '.

The A-theory reading asserts that what we achieve by the judgment stroke corresponds to the additional component of judging: To judge that $p$, one must express the claim that $p$ is the True in addition to grasping $\langle p\rangle$.

The assertion theory of truth starts with $\left(\mathrm{A}_{1}\right)$, Its critical claim (Greimann 2007: 134) is that

$\left(A_{2}\right)$ The judgment stroke is a truth-operator by virtue of which we can express a genuine truth-claim.

The assertion theory further argues that

$\left(\mathrm{A}_{3}\right)$ Assertoric sentences are of the form ' $F \Phi^{\prime} .{ }^{12}$

$\left(\mathrm{A}_{1}\right),\left(\mathrm{A}_{2}\right)$, and $\left(\mathrm{A}_{3}\right)$ imply one of the main theses of the assertion theory that

$\left(C_{1}\right)$ Truth is expressed by the form of assertoric sentences.

12. The assertoric sentences of the natural language do not reveal this form clearly. For instance, the sentence 'The Republic of Korea is surrounded by sea' is an assertoric sentence with which we can assert that Republic of Korea is surrounded by sea. However, with the very same sentence, we can also just put forward the idea that the Republic of Korea is surrounded by sea without making any commitment to its truth. Frege believes that this is one way the natural language is flawed and hides the logical form of assertoric sentence. See Greimann 2007) and Künne 2013). 
The judgment stroke is constitutive of the form of assertoric sentences and it is a truth-operator by which we can express a genuine truth-claim. Hence, $\left(\mathrm{C}_{1}\right)$.

One might challenge $\left(\mathrm{A}_{2}\right)$. Frege considers a truth claim to have the form of ' $\langle p\rangle$ is true'. This shows that, for Frege, legitimate truth-bearers are thoughts and hence a truth-claim should be about a thought. However, the claim we express by the judgment stroke in

is that $\Phi$ is identical with the True, which is not about thoughts but about truthvalues.

The A-theory reading (Greimann 2007 136) responds by saying that the sense of a sentence ' $p$ ' is identical with the sense of 'the truth-value of $\langle p\rangle$ '. Therefore, the claim that $p$ is the True is identical with the claim that the truth-value of $\langle p\rangle$ is the True. The claim expressed by the judgment stroke, that $p$ is the True, is then a claim about the thought $\langle p\rangle$. In the assertion theory of truth, the ordinary truth claim ' $\langle p\rangle$ is true' is analyzed as follows:

$\left(\mathrm{A}_{4}\right)\langle p\rangle$ is true if and only if ${ }_{A}$ the truth-value of $\langle p\rangle$ is the True

where ' $p$ if and only if $A$ ' or ' $p$ iff $_{A} q$ ' entails ' $\langle p\rangle$ is identical to $\langle q\rangle$ and $\langle q\rangle$ constitutes the analysis of $\langle p\rangle^{\prime} .^{13}$

We can construe the role played by the notion of truth in judging and asserting as follows. The judgment stroke is a truth-operator, and to combine it with a proper sentence into an assertoric sentence is to make a judgment. Thus, the role played by the notion of truth in judging should correspond to the role played by the judgment stroke in an assertoric sentence. The role of the judgment stroke in an assertoric sentence is to express the truth-claim that the truth-value of a thought is identical with the True. The role played by the notion of truth is then to identify the truth-value of a given thought with the True (Greimann 2004: $434 ; 2007$; $136-138 ; 2015$; 12). Thus, acknowledging the truth of a thought is identifying the truth-value of the thought with the True.

Now, $\left(\mathrm{A}_{4}\right)$ seems to have a problematic implication: Truth is a property of thoughts. To say $\langle p\rangle$ has the True as its truth-value is to say that $\langle p\rangle$ has the property of having the True as its truth-value. $\left(\mathrm{A}_{4}\right)$ looks like the claim that this property of $\langle p\rangle$ constitutes the truth of $\langle p\rangle$. Frege cannot accommodate this. However, the A-theory reading claims that the assertion theory of truth has additional components that cancel out this implication. The A-theory reading finds these components in Frege's notion of saturation (of a concept).

13. Greimann 2008 \$2) remarks that ' $x$ is the True' is hence a truth-predicate in Frege's framework. More precisely, where ' $\Psi$ ' is a proper declarative sentence which constitutes the name of a truth-value, we can say that ' $\Psi$ is the True', and this is synonymous with 'The truth-value of $\langle\Psi\rangle$ is the True'. 
What we call 'properties' fall under the category of concept in Frege's framework. Concepts are functions the value of which is always a truth-value. Frege (1891: 1892b) looks upon functions as unsaturated. To say that a function is unsaturated is to say that a function has empty places that must be saturated by arguments in order for the function to provide an object as its value. Concepts are also unsaturated. Saturated, they provide a truth-value as its value. A concept is thus predicative (Greimann 2007, 128-129).

On the saturation of (a particular kind of) concepts, Frege writes,

In the sentence 'Two is a prime' we find a certain relation designated: that of subsumption. We may also say the object falls under the concept prime .... This also creates the impression that the relation of subsumption is a third element supervenient upon the object and the concept. This isn't the case: the unsaturatedness of the concept brings it about that the object, in effecting the saturation, engages immediately with the concept, without need of any special cement. Object and concept are fundamentally made for each other, and in subsumption we have their fundamental union. 1906b: 178)

Frege is talking about a particular kind of saturation: Subsumption. Frege seems to be suggesting that subsumption as a kind of saturation is not a genuine relation: Subsumption occurs just because concepts immediately engage with objects by their own nature and hence no special cement or relation is necessary for that. It also seems that Frege identifies this kind of saturation with the relation of an object o falling under the concept $C$. If so, Frege is here arguing that the relation of $o$ falling under $C$ is not a genuine relation. That is indeed how the A-theory reading understands this passage. Greimann, who suggests the A-theory reading, writes,

The relation that Frege calls "subsumption" is a special case of saturation. According to the system in Begriffsschrift, this relation holds between an object and a concept if the result of the concept's saturation by the object is a fact .... (Greimann 2007, 130; italics mine)

The result of the concept prime's saturation by the number 2 is 2's being prime. 2's being prime is a fact; 2 is prime. Therefore, what Greimann is arguing here is that subsumption holds between 2 and the concept prime if 2 is prime. Subsumption as such is naturally identified with the relation of ofalling under $C$; '2 falls under the concept prime' is equivalent to ' 2 is prime'. What is crucial is that this kind of relation is found in every sentence. For instance, say John loves Mary. We may say that John stands in the relation love to Mary. This looks like an example of another type of saturation: the relation of an object $o_{1}$ 's standing in the relation $R$ to an object $o_{2}($ Greimann 2007 137). If subsumption or the relation ofalling under $C$ 
is not a genuine relation, it seems, this new type of saturation or the relation $o_{1}$ 's standing in $R$ to an object $o_{2}$ should not be a genuine entity.

On these different relations, the A-theory reading says,

Note that because of the very special role that this relation plays in judgment it cannot be substituted by ordinary relations. While the role of ordinary relations is to form the predicative part of judgments, the role of saturation is to connect this part with the non-predicative parts. Therefore, saturation, subsumption and kindred relations like the standing of two objects in a relation ... form a logical category sui generis: they are, anachronistically speaking, not genuine relations, but "non-relational ties" whose sole task is to tie the predicative and the non-predicative parts of judgments together. Let us call these very specials relations "logical relations". (Greimann 2007: 131)

The A-theory reading continues arguing that logical relations themselves are 'neither saturated nor unsaturated' (Greimann 2007 131). This has an ontological consequence, because Frege's ontology consists only of the category of saturated things, that is, objects, and that of unsaturated, that is, functions. But logical relations fall under none of those categories. They are 'no-thing' (Greimann 2007: 131). Accordingly, the assertion theory of truth has the following:

$\left(\mathrm{A}_{5}\right)$ Logical relations are neither objects nor concepts.

Lastly, the A-theory reading (Greimann 2007 137-138) attributes the following claim to Frege:

$\left(\mathrm{A}_{6}\right)$ The truth-value of $\langle p\rangle$ is the True iff $_{A}$ the logical relation relevant to $\langle p\rangle$ obtains.

The A-theory reading supports $\left(\mathrm{A}_{6}\right)$ by the following passage from Grundgesetze:

We say that an object $\Gamma$ stands in the relation $\Psi(\xi, \zeta)$ to the object $\Delta$ if $\Psi(\Gamma, \Delta)$ is the True. Likewise we say that the object $\Delta$ falls under the concept $\Phi(\xi)$ if $\Phi(\Delta)$ is the True. $(1893: 8)^{14}$

The logical relation relevant to $\langle\Phi(\Delta)\rangle$ is subsumption. Frege seems to be stating that the fact that the truth-value of $\langle\Phi(\Delta)\rangle$ is the True consists in the fact that the

14. Greimann claims that 'Frege explains subsumption in terms of truth' (2007. 138). It is not certain that the passage really verifies Greimann's reading. Nor is it certain that Greimann needs this point for his main idea that, for Frege, deciding that a thought is true is just deciding that the logical relation relevant to the thought obtains. 
subsumption obtains between $\Phi(\xi)$ and $\Delta$, and that the fact that the truth-value of $\langle\Psi(\Gamma, \Delta)\rangle$ is the True consists in the obtaining of the logical relation relevant to it. For every thought, there is always a logical relation relevant to it. Based on the above passage, the A-theory reading holds that Frege would be willing to say that the truth-value of a thought being the True consists in the obtaining of the relevant logical relation. Hence, $\left(\mathrm{A}_{6}\right)$.

$\mathrm{By}\left(\mathrm{A}_{4}\right)$ and $\left(\mathrm{A}_{6}\right),\langle p\rangle$ is true iff ${ }_{A}$ the logical relation relevant to $\langle p\rangle$ obtains. $\mathrm{By}\left(\mathrm{A}_{5}\right)$, we have another main thesis of the assertion theory:

$\left(C_{2}\right)$ Truth is neither a concept nor an object. (Greimann 2007. 147)

Thus, there is no problem with attributing the assertion theory of truth to Frege. In the assertion theory, truth is not a concept, that is, a property. It is not an object, either. It is not even an entity.

Recall that the role of the notion of truth in judging or asserting, embodied by the judgment stroke, is to identify the truth-value of a thought with the True. Given $\left(\mathrm{A}_{6}\right)$, what we achieve by this identification is to decide that the relevant logical relation obtains. In judging and asserting, we identify the truth-value of a thought with the True and thereby decide that the relevant logical relation obtains. This is Frege's final answer to the question as to the role of the notion of truth in judging and asserting according to the A-theory reading (Greimann 2007; 138).

The A-theory reading fits the textual evidence we have seen in the last section. It can explain why Frege contends that truth is not a property by saying that truth is the obtaining of a logical relation that is not even a genuine entity. Because truth is not even an entity, it is indefinable as Frege argues. Finally, truth is still predicative because it is a tie among different entities.

However, I argue, Frege is not an assertion theorist of truth.

\section{Frege is not an Assertion Theorist}

The assertion theory of truth endorses

$\left(\mathrm{A}_{1}\right)$ We express the claim that $\Phi$ is the True by putting ' $r$ ' in front of ' $\Phi$ '.

Frege seems to adopt $\left(\mathrm{A}_{1}\right)$.

By writing

$$
\vdash 2+3=5
$$

[we are] saying that it is the True. (Frege 1891: 34) 
However, I maintain that $\left(\mathrm{A}_{1}\right)$ is false. What we achieve by putting ' $F$ ' in front of ' $\Phi$ ' cannot be to express the claim that $\Phi$ is the True. To express such a claim is to predicate the property being (identical with) the True of $\Phi$ or to judge (assert) that $\Phi$ is the True. Neither of them can be what we do by putting ' $F$ ' in front of $\Phi$.

First, what we accomplish by writing down ' $\Phi$ ' cannot be to predicate the property being the True of $\Phi$. All we achieve by predicating is to grasp a thought. Nonetheless, one cannot make a judgment by grasping a thought, as we have seen in Section 2. Begriffsschrift further buttresses this point. The horizontal '_- ' denotes the concept that outputs the True given the True and the False given anything other than the True; it denotes the concept being the True. Through writing down ' - $\Phi^{\prime}$, we already predicate the property being the True of $\Phi .{ }^{15}$ But judgment is not yet achieved. What the judgment stroke does is something else.

Secondly, what we achieve by putting the judgment stroke in front of ' $~ \Phi$ ' cannot be to judge that $[\Phi]$ is the True, either. (' $[\tau]$ ' is a proper name for a truth value even when ' $\tau$ ' is a sentence.) If that is what we do, Frege is committed to the claim that judging that $[\Phi]$ is the True is necessary for judging that $\Phi$. We have to judge that $[\Phi]$ is the True in order to judge that $\Phi$. To judge that $[\Phi]$ is the True, we also have to judge that $[[\Phi]$ is the True] is the True. Hence, we should judge that $[[\Phi]$ is the True] is the True in order to judge simply that $\Phi$. This regress will go forever. We cannot avoid this problem by saying that $\langle\Phi\rangle$ is the same as $\langle[\Phi]$ is the True $\rangle$ and so the infinite regress is not vicious. For the additional component of judging that $\Phi$ cannot be the act of judging that $\Phi$ itself.

The above infinite regress is something Frege is well aware of, according to a number of commentators (Heck 2007: 2012; Heck \& May 2018; Kremer 2000; Pagin 2001; Ricketts 1996). In his 'Logic', Frege writes,

If, for example, we wished to say 'an idea is true if it agrees with reality' nothing would have been achieved, since in order to apply this definition we should have to decide whether some idea or other did agree with reality. ... The same would hold of any definition of the form ' $A$ is true if and only if it has such-and-such properties or stands in such-and-such a relation to such-and-such a thing'. In each case in hand it would always come back to the question whether it is true that $A$ has such-and-such properties .... 1897, 128-129) ${ }^{16}$

This is Frege's famous argument for the indefinability of truth. Note the kind of definition Frege is targeting here. If there is such a definition of truth, it is a property of a truth-bearer $A$. Also, note that Frege is talking about the act of deciding whether something is true; he is talking about judgment qua acknowledgment of truth. Scholars claim that if we take these points into account,

15. Greimann (2007: 2014) himself admits this point.

16. The same kind of argument is found in 'Thought' (1918a 327). 
we can see what Frege is getting at here. Heck writes,

Suppose we do think of truth as a property of thoughts. Then, the idea that judgment is admission of a thought's truth becomes the idea that judging is a form of predication: judging is predicating truth of a thought. ... Predication in this sense is itself a sort of judgment: To predicate truth of the thought that $p$ is just to judge that the thought that $p$ is true, that is, to judge that it is true that $p .{ }^{17}$ If so, however, then judging that it is true that $p$ is predicating truth of the thought that it is true that $p$, that is, judging that it is true that it is true that $p$. And the regress is vicious, since the sense in which judgment is predication of truth was meant to be constitutive. (Heck 2012, 47)

Though Heck is using a thought as a truth-bearer, this argument does not hinge on the nature of thought at all. The point is that, given that judging is acknowledging the truth of a truth-bearer, truth cannot be a property and hence there cannot be a correct definition of truth that takes it qua a property. ${ }^{18}$ What is crucial is that the infinite regress we pointed out in the previous paragraph appears to be of the same kind. It is a case of this infinite regress where a truth-bearer is an object and truth is the property being identical with the True. It seems improbable that Frege would make the same kind of infinite regress, which he is well aware of, produced by Begriffsschrift.

Some scholars interpret Frege's argument differently. Baldwin (1995) and Grossmann (1969) maintain that Frege is pointing to a sort of circularity. Wolfgang Künne (2003 $132-133 ; 2008$, 12-14) fully develops this circularity reading. ${ }^{19}$ Still, this reading and the infinite regress reading concur in many points. First, the proponents of the circularity reading agree that this argument concerns judgment qua acknowledgment of truth. Second, they also take it that this argument aims

17. Heck's statement 'Predication in this sense is itself a sort of judgment' might seem to conflict with Frege's views on predication. However, the phrase 'in this sense' seems to mean 'constitutive of judgment'. Heck's point is then that, given the assumption that truth is a property, truth-predication must constitute judgment and truth-predication as constitutive of judgment must be judgment. If so, Heck is not going against Frege's own views on predication.

18. Frege elucidates judgment as acknowledgment of truth throughout his entire career. The object reading respects this point. But it claims that the way Frege understands this elucidation has changed. The early Frege takes truth as a property and hence claims that judgment qua acknowledgment of truth is predication of truth. See Frege (1879 §3). But the later Frege gives up this predicative conception. One of the reasons why he gives it up consists in the indefinability argument according to the object reading (Heck|2012 \$2.3; Textor 2010 621-624). Frege's alternative understanding of judgment qua acknowledgment of truth can be found in 'On Sense and Reference' $(1892 \mathrm{C})$ as I explain below.

19. Greimann (2007) is also a proponent of the circularity reading. However, his reading depends on the notion of logical relation he ascribes to Frege. As I argue below, ascribing this notion to Frege is not warranted. 
to show that truth cannot be defined as a property. Thirdly, they accept that Frege's point is that, if truth is a property, we should judge that a truth-bearer has the property constitutive of truth in order to judge that the truth-bearer is true (Künne 2008. 14). The difference between the infinite regress and the circularity reading consists in how they understand Frege's last point. The former regards it as showing that a vicious regress is produced if truth is a property, while the latter regards it as showing that a vicious circularity is produced if truth is a property. Again, if we say what we achieve by the judgment stroke is to assert that $[p]$ is the True, it follows that we must assert that $[p]$ is the True to assert that $p$. Whichever reading of the argument one may endorse, one would agree that this implication is problematic for Frege.

In conclusion, what we achieve by the judgment stroke cannot be to predicate being the True of $\Phi$ or to assert that $\Phi$ is the True. Thus, what is achieved by the judgment stroke cannot be to express the claim that $\Phi$ is the True. 'Saying that $[2+3=5]$ is the True' in 'Function and Concept' cannot mean 'expressing the claim that $[2+3=5]$ is the True'. $\left(\mathrm{A}_{1}\right)$ is false.

The proponent of the A-theory reading might object that we express such a claim by asserting. The A-theory reading, however, cannot say so in fact. The question we are dealing with is how we make a judgment or an assertion. We know that grasping a relevant thought is insufficient for doing so. $\left(\mathrm{A}_{1}\right)$ that concerns the judgment stroke is the A-theory reading's answer to what the additional component of judging is. It is arguing that by expressing the identity claim (through the judgment stroke), we achieve assertion, but not the other way around.

If $\left(\mathrm{A}_{1}\right)$ is false, $\left(\mathrm{A}_{2}\right)$ is false:

$\left(A_{2}\right)$ The judgment stroke is a truth-operator by means of which we express a genuine truth-claim.

If $\left(\mathrm{A}_{2}\right)$ is the case, then what we achieve by the judgment stroke is to express a truth-claim about $\Phi$ (or $\langle\Phi\rangle$ ). We have just shown that the consequent is false. Therefore, $\left(\mathrm{A}_{2}\right)$ is false.

The A-theory reading might argue that Frege can still be taken as accepting a good chunk of the assertion theory of truth. If Frege still accepts these:

$\left(\mathrm{A}_{4}\right)\langle p\rangle$ is true iff $_{A}$ the truth-value of $\langle p\rangle$ is the True;

$\left(\mathrm{A}_{5}\right)$ Logical relations are neither objects nor concepts;

$\left(\mathrm{A}_{6}\right)$ The truth-value of $\langle p\rangle$ is the True iff $_{A}$ the logical relation relevant to $\langle p\rangle$ obtains; 
a thesis of the assertion theory sustains: $\left(C_{2}\right)$ Truth is neither a concept nor a property. However, I argue that Frege accepts neither $\left(\mathrm{A}_{5}\right)$ nor $\left(\mathrm{A}_{6}\right)$.

Recall that the A-theory reading ascribes $\left(\mathrm{A}_{5}\right)$ to Frege by appealing to the following passage from 'On Schoenflies':

In the sentence 'Two is a prime' we find a certain relation designated: that of subsumption. We may also say the object falls under the concept prime .... This also creates the impression that the relation of subsumption is a third element supervenient upon the object and the concept. This isn't the case: the unsaturatedness of the concept brings it about that the object, in effecting the saturation, engages immediately with the concept, without need of any special cement. Object and concept are fundamentally made for each other, and in subsumption we have their fundamental union. 1906b: 178)

The A-theory reading, I believe, correctly points out that Frege argues that subsumption qua a kind of saturation is not a genuine relation. The A-theory reading also assumes that 'subsumption' means 'the relation of o falling under $C^{\prime}$ and concludes that the relation of $o$ falling under $C$ is not a genuine relation. I will contend that the assumption leads to a misinterpretation of this passage. Before that, however, I first flag a problem with the inference of the A-theory reading.

I remind you of the point that saturating a function is merely providing an argument for the function. In '[Comments on Sense and Reference]', Frege writes,

Accordingly I call the function itself unsaturated, or in need of supplementation, because its name has first to be completed with the sign of an argument if we are to obtain a reference that is completed in itself. I call such a reference an object and, in this case, the value of the function for the argument that effects the supplementing or saturating. (1892a 119)

Frege's point is evident: A function is saturated if it is provided with an argument for its empty place. A saturated function yields an object as its value. ${ }^{20}$

The concept prime is saturated by the object 2; it takes 2 as argument and yields the True as value. Let us call the saturation of a concept by an object 'OC-saturation'. OC-saturation diverges from the relation of $o$ falling under $C$. The concept prime is also saturated by 4 ; it also takes 4 as argument yielding the False as value in this case. However, 4 does not fall under the concept prime. Of course, the A-theory reading is aware of this. That is why it says,

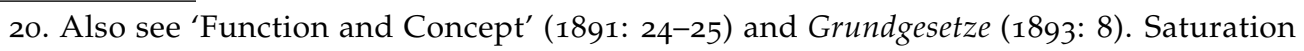
can also be explained in the level of sense. See Frege (1923). Here, saturating or completing is simply fulfilling the empty space of the sense of a concept. 
The relation that Frege calls "subsumption" is a special case of saturation. According to the system in Begriffsschrift, this relation holds between an object and a concept if the result of the concept's saturation by the object [i.e., OC-saturation] is a fact .... (Greimann 2007; 130; italics mine)

The A-theory reading is taking a case of subsumption as that of OC-saturation where the relation subsumption also obtains between an object and a concept, that is, where the object also falls under the concept.

In the second half of the passage from 'On Schoenflies', however, Frege appears to maintain that OC-saturation in general is not a genuine relation.

The unsaturatedness of the concept brings it about that the object, in effecting the saturation, engages immediately with the concept, without need of any special cement. (Frege 1906b; 178)

Say Frege's claim concerns OC-saturation in general. To directly proceed from it to the conclusion that the relation of subsumption or ofalling under $C$ is not a genuine relation, the A-theory reading should make the following inference: 'Since a case of OC-saturation where the relation of $o$ falling under $C$ also obtains is always a case of OC-saturation and OC-saturation is a pseudo relation, the relation of o falling under $C$ is also a pseudo relation.' This inference is invalid as the following inference is invalid: 'Since purified water is always water and water is a natural kind, being purified is a natural kind.'

An immediate response would be that 'the saturation' in the previous quotation just means 'subsumption'-'OC-saturation where subsumption obtains between the object and the concept or where the object falls under the concept'. This response relies on the fundamental assumption of the A-theory reading: What Frege refers to by 'subsumption' is the relation of o falling under C. Probably, the assumption would be based on the first two statements of the passage:

In the sentence 'Two is a prime' we find a certain relation designated: that of subsumption. We may also say the object falls under the concept prime .... (Frege 1906b; 178)

However, these statements must be read differently. A line-by-line examination of the passage would help to see this.

Let me present Frege's second statement altogether with the omitted part:

We may also say the object falls under the concept prime, but if we do so, we must not forget the imprecision of linguistic expression we have just mentioned. (Frege 1906b. 177)

Quoting this passage, I omitted the second half of this statement because the A-theory reading does not explain what Frege means by the imprecision of 
linguistic expression we have just mentioned'. However, it is extremely important to see what he means by that. Here, Frege is pointing out a problem with the locution ' 2 falls under the concept prime'. The problem is explained in the previous passage.

We can scarcely avoid using such expressions as 'the concept prime'. Here there is no trace left of unsaturatedness, of the predicative nature. Rather the expression is constructed in a way which precisely parallels 'the poet Schiller'. So language brands a concept as an object .... (Frege 1906b. 177)

The problem is that the phrase 'the concept prime' leaves no empty place and hence is a proper name. Strictly speaking, the concept prime is an object. This is 'the paradox of the concept horse' in 'On Concept and Object' (Frege 1892b): The concept horse is not a concept. This must be what Frege refers to by 'the imprecision of linguistic expression we have just mentioned'. Given this problem, we can expect a further problem with the locution ' 2 falls under the concept prime'. It leads to the contention that the relation of subsumption is a relation between two objects: 2 and the concept prime. This is exactly what Frege is saying:

This also creates the impression that the relation of subsumption is a third element supervenient upon the object and the concept. (Frege 1906b: 178)

However, Frege denies it:

This isn't the case .... (Frege 1906b: 178)

Subsumption is not such a relation. But the relation of $o$ falling under $C$ is. The number 2 surely falls under the concept prime. This is a relation between the two objects: 2 and the concept prime. What Frege means by 'the relation of subsumption' cannot be 'the relation $x$ falling under $y$ '.

The problem Frege is dealing with, I believe, is a classical one. Say the relation of subsumption obtains between two objects. Say we express this relation by ' $x$ falls under $y$ '. In the sentence ' 2 falls under the concept prime', we find a relation designated: the relation among 2 , the concept prime, and the relation of subsumption. We may also say that the relation of subsumption obtains between 2 and the concept prime. Note that the relation of subsumption is again an object. This leads to the claim that there is the three-place relation of $x$ obtaining between $y$ and $z$ that obtains between the relation of subsumption, the concept prime and 2. Now, in the sentence 'the relation of subsumption obtains between 2 and the concept prime', we find a relation designated: the relation among 2, the concept prime, the relation of subsumption, and of three-place obtaining. This regress, an instance of what we often call 'Bradley's regress' (Perovic 2017), is what Frege is getting at. His point is that if we take the relation we designate in ' 2 is prime', 
that is, subsumption, as a relation that obtains between two items, this regress is unstoppable. Subsumption must not be such a relation.

In the second half, Frege suggests an alternative understanding of subsumption:

This isn't the case: the unsaturatedness of the concept brings it about that the object, in effecting the saturation, engages immediately with the concept, without need of any special cement. Object and concept are fundamentally made for each other, and in subsumption we have their fundamental union. (Frege 1906b: 178)

The alternative is that subsumption is a kind of saturation: OC-saturation. Although Frege is just talking about OC-saturation, I believe his point is perfectly general. Functions are unsaturated. Due to its nature, a function immediately saturates itself with an argument, yielding an object as the value for the argument. A function does so with each and every possible argument without any discrimination. No special cement is hence necessary for saturation in general. Perhaps, this may be one reason why Frege maintains that a function should always be totally defined (Frege 1891: 33). ${ }^{21}$ OC-saturation is the case of a single object saturating an one-place first level concept, that is, a concept that receives an object as an argument and yields a truth-value as the value for the argument. What Frege argues is that subsumption is just OC-saturation, which is not a genuine relation. There are different kinds of saturation: The saturation of a two-place first-level function by two objects in order, ..., the saturation of a one-place second-level function by a first level function, .... By the same token, all of them are not genuine relations.

Now, let us return to the opening of the passage.

In the sentence 'Two is a prime' we find a certain relation designated: that of subsumption. (Frege 1906b 178)

Substituting 'Two is a prime' with 'Four is a prime' is fine; the same kind of relation is designated by the latter. The relation of subsumption is thus introduced $q u a$ the relation that is designated by the sentences of the form ' $n$ is prime'. Then, Frege says,

We may also say the object falls under the concept prime .... (Frege 1906b. 178)

What Frege is saying seems to be that the locution ' $n$ falls (or subsumes) under the concept prime' is our attempt to capture the relation that is designated by the sentences of the form ' $n$ is prime'. Given this locution, it is comprehensible

21. For the detailed discussion of this point, see Blanchette (2012) and Heck (2012). 
to call such a relation 'subsumption'. Frege's point is that subsumption, qua the relation designated by the sentences of the form ' $n$ is prime', must be sharply distinguished from the relation of $n$ 's falling under the concept prime. The former is just OC-saturation, while the latter is a two-place relation designated by the misleading locution ' $n$ falls under the concept prime'.

What Frege is doing seems to be clear. He is diagnosing Bradley's regress as a pseudo problem that results from our failing to see the unsaturatedness of functions. If we understand the unsaturatedness of functions, we can also understand that what obtains between functions and their arguments is not a genuine relation. Therefore, the regress does not exist. We fail to see this because natural language names functions in the way it names objects, as it does in the locution ' 2 falls under the concept prime'. Of course, we cannot avoid that kind of locution in natural language (Frege 1906b 177). Nonetheless, we need to be careful because the locution misfires. To establish that it misfires is the whole point of the passage.

Now, the ascription of $\left(\mathrm{A}_{5}\right)$

$\left(A_{5}\right)$ Logical relations are neither objects nor concepts

to Frege is unwarranted. That is not what he puts forward in the passage. What he is saying is that saturation is not a genuine relation. In the end, Frege has never said that 'logical relations' are not genuine entities.

Note that the ascription of $\left(\mathrm{A}_{6}\right)$

(A6) The truth-value of $\langle p\rangle$ is the True iff $_{A}$ the logical relation relevant to $\langle p\rangle$ obtains,

to Frege depends on this passage in Grundgesetze:

We say that an object $\Gamma$ stands in the relation $\Psi(\xi, \zeta)$ to the object $\Delta$ if $\Psi(\Gamma, \Delta)$ is the True. Likewise we say that the object $\Delta$ falls under the concept $\Phi(\xi)$ if $\Phi(\Delta)$ is the True. (Frege 1893: 8)

The A-theory reading takes it that Frege is providing a serious philosophical analysis-as serious as $\left(\mathrm{A}_{6}\right)$. This cannot be the case. It is not acceptable to analyze a precise notion by a notion that is not just imprecise but also fundamentally problematic. Frege would deny these claims if they were to be read as seriously as $\left(\mathrm{A}_{6}\right)$.

What Frege is doing here is not to put forward an instance of $\left(\mathrm{A}_{6}\right)$, but to provide the natural language analogues of the Begriffsschrift expressions like ' $\Psi(\xi, \zeta)^{\prime}$ or ' $\Phi(\Delta)$ ' in order to elucidate the logical forms of the thoughts expressed by those expressions. He needs these analogues to make his readers understand the 
meaning of these odd-looking strings of symbols. ${ }^{22}$ In that restricted sense, we can say, Frege is explaining the Begriffsschrift expressions. However, it cannot be the case that Frege is providing instances of $\left(\mathrm{A}_{6}\right)$, which is a philosophical analysis.

Frege accepts none of the main theses of the assertion theory of truth. Therefore, it seems implausible to say that Frege is an assertion theorist of truth.

\section{The Return of the Object Reading}

Although the A-theory reading is not satisfactory, I believe, it makes valuable observations of Frege's conception of truth:

$\left(\mathrm{F}_{1}\right)$ Truth is whatever we express by asserting;

$\left(F_{2}\right)$ To assert that $p$ is to identify the reference of ' $p$ ' with the True.

The remarks of Frege's we have seen so far definitely suggest $\left(\mathrm{F}_{1}\right)$ and $\left(\mathrm{F}_{2}\right)$. The problem with the A-theory reading is the way it explains them. Its claims, $\left(\mathrm{A}_{1}\right)$ $\left(\mathrm{A}_{6}\right)$, do not constitute a proper interpretation of $\left(\mathrm{F}_{1}\right)$ and $\left(\mathrm{F}_{2}\right)$. I propose that the proper way to understand them is rather provided by the object reading.

Recall that $\left(\mathrm{F}_{2}\right)$ is found in the following passage from 'Function and Concept'.

[B]y writing

$$
\vdash 2+3=5
$$

We assert that $2+3$ equals 5 . Thus here we are not just writing down a truth-value, as in

$$
2+3=5,
$$

but also at the same time saying that it is the True. (Frege 1891: 34; italics mine)

The A-theory reading considers $\left(\mathrm{F}_{2}\right)$ as the claim that to assert that $p$ is to express the claim that $[p]$ is the True. As we have seen in Section 3, to assert that $p$ cannot be to express such an identity claim. We need a different way of reading the identification of $[p]$ with the True in $\left(\mathrm{F}_{2}\right)$,

In 'On Sense and Reference', Frege writes,

But so much should already be clear, that in every judgment, no matter how trivial, the step from the level of thoughts to the level of reference (the objective) has already been taken. (1892c:64)

22. There is a further reason why he is using this kind of locution, which is related to the previous subject-predicate analysis of content. For this reason, see Frege (1892a). 
Judgments can be regarded as advances from a thought to a truth value. (1892C: 65)

Frege is elucidating that to judge (or assert) that $p$ is to take a step from a thought (i.e., a sentential sense) to a truth value (i.e., a sentential reference). We can take the same kind of step with any kind of name:

It is doubtful whether the name 'Odysseus,' ... has reference .... Whoever does not admit the name has reference can neither apply nor withhold the predicate. But in that case it would be superfluous to advance to the reference of the name. $(1892 \mathrm{C} ; 62)$

It is the striving for truth that drives us always to advance from the sense to the reference [of a name such as 'Odysseus']. (1892C: 63)

To comprehend what it is to take a step from a name's sense to its reference, we need to note the gap between the knowledge of sense and of reference Frege mentions early in this paper. In general, the knowledge of a proper name's sense does not directly lead to that of its reference.

Comprehensive knowledge of the reference [of a proper name] would require us to be able to say immediately whether any given sense belongs to it. To such knowledge we never attain. (1892c: 58)

If the knowledge of the sense of a proper name directly leads to the knowledge of its reference, we should be able to tell immediately whether any given sense belongs to a certain reference. However, Frege seems to be denying the consequent and concluding that we never have comprehensive knowledge of the reference. The knowledge of the sense of a proper name does not even let us know whether the name has a reference:

In grasping a sense, one is not certainly assured of a reference. (1892C:58)

We can grasp the sense of 'Odysseus' in 'Odysseus fought in the Trojan war'; but we do not know whether the name really has a reference. To take a step from a name's sense to its reference is to (attempt to) advance from the knowledge of the name's sense to that of the name's of reference. Say we come across the name 'Odysseus'. By knowing its sense, we understand that the name refers to an object if it refers to any. Now, if we pick up an object $O$ and identify it with the reference of 'Odysseus', that is, Odysseus, we thereby take a step from the sense of 'Odysseus' to $O$. Likewise, if we pick up a truth value and identify it with $[p]$, then we thereby take a step from $\langle p\rangle$ to the truth-value. Note that taking a step from a name's sense to its reference, thusly understood, is an act of identification. Then, Frege's elucidation of judgment qua identification in 'Function and Concept' 
is clearly related to the above elucidation in 'On Sense and Reference'. Specifically, the phrase 'saying that $[2+3=5]$ is the True' in 'Function and Concept' can be taken as meaning 'taking a step from $\langle 2+3=5\rangle$ to the True'. What Frege is trying to say there is then that when we judge that $p$, it is the True that we pick up and identify [p] with.

Frege's elucidation of judgment in 'On Sense and Reference' provides us with a clue to the kind of identification he has in his mind when he argues that to judge that $p$ is to identify $[p]$ with the True. To take a step from the level of sense to the level of reference is comparable to the speaker-action of reference: the act of referring to an object by a name. First, the speaker-action of reference is a sort of identification. When I say 'Toby is working on linguistics', I refer to one of my friends by 'Toby'. Referring to the person by 'Toby', I thereby identify him with Toby. Second, a person who takes 'Odysseus' as a fictional name would never refer to a real object by it while a person who takes Odysseus as a historical figure would willingly do so-just as the former would never take a step from the sense of 'Odysseus' to the reference while the latter would willingly do so. Note that the identification we make when we refer to an object by a name is by no means an act of expressing an identity claim: Referring to my friend by 'Toby', I do not thereby predicate the property being Toby of him or assert that he is Toby. The speaker-reference provides a model for the kind of identification Frege needs when he characterize judgment as identification. In particular, judging that $p$ is comparable to referring to the True by ' $p$ ', as Heck and May (2018), Heck (2007; 2012) and Textor (2010) point out.

I am not arguing that Frege means by 'taking a step from a thought to the True' the speaker-act of referring to the True via $\langle p\rangle$. Nor am I suggesting that Frege has ever described judgment as such a speaker-act. My contention is only that the speaker-reference supplies a model for the kind of identification Frege has in his mind when he elucidates judgment qua identification.

One might object by pointing out that, on ' $r$ ', Frege writes,

The assertion sign ... does not serve ... to designate an object. ' $-2+3=$

5' does not designate anything; it asserts something. (Frege 1891; 34n)

He also writes in Grundgesetze,

$$
0^{2}=4^{\prime}, 1^{2}=4^{\prime}, 2^{2}=4^{\prime}, 3^{2}=4^{\prime}
$$

... It is already clear from this that I do not want to assert anything yet when I simply write down an equation, but that I merely designate a truth-value .... (Frege 1893: 7)

The challenge is that if referring is just designating, writing down ' $P$ ', that is, judging that $p$, cannot be compared to referring to the True. 
However, to designate a truth value is to write down a term intended to be the proper name for a truth value, without really deciding whether the written term indeed refers to a truth value or which of the True and the False it refers to.

Above it is already stated that with a mere equation no assertion is yet to be found; with ' $2+3=5$ ' only a truth value is designated, without its being said which one of the two it is. (Frege 1893: 9; italics mine)

Designating as such is sharply distinguished from referring to a truth value. This is because, if I refer to an object by a name, I am specifying the reference of the name. If I refer to the True by ' $2+3=5$ ', I am specifying the reference of the sentence.

Hence, it looks as though the speaker-act of reference can work as a model for the kind of identification Frege has in his mind when he takes judging that $p$ as identifying $[p]$ with the True. In other words, it appears plausible to say that what Frege takes as achieved by asserting that $p$ is comparable to referring to the True by ' $p$ '. The observation $\left(\mathrm{F}_{1}\right)$

$\left(F_{1}\right)$ Truth is whatever we express by asserting,

now goes hand in hand with the object reading that truth is the True for Frege. We express the True by asserting, in the sense that what we achieve by asserting can be compared to referring to the True. Frege's remarks on truth seem to be pointing to the object reading.

Of course, Greimann's criticisms against the object reading still remain. In the remainder, I show that his criticisms can be satisfactorily responded to.

Criticism 1. Frege does not mention truth-values at all in 'Thought'.

I argue that this fact does not show that truth is not the True for Frege. He writes,

The Bedeutung of the word 'true' seems to be altogether sui generis. May we not be dealing here with something which cannot be called a property in the ordinary sense at all? In spite of this doubt I will begin by expressing myself in accordance with ordinary usage, as if truth were property, until some appropriate ways of speaking is found. (1918a 328-9; italics mine)

Note that Frege is using the term 'property' instead of 'concept'; he is complying with ordinary terminology. This is because 'Thought' along with 'Negation' (1918b) and 'Compound Thoughts' (1923) is Frege's attempt to advertise his conception of logic to the people who are not familiar with his formal system. Therefore, he is trying not to use any technical term like 'concept' here. If so, Frege's explicit declaration that he would follow the ordinary usage of 'true' rather 
appears to show that he is uncomfortable with the ordinary usage according to which truth looks like a property. Also, the fact that he does not mention truthvalues here seems to only mean that he does not have to depend on truth being the True in order to make his points in this paper.

In 'Thought', the points directly relevant to the nature of truth are centered around the first few pages of the paper (Frege 1918a: 325-329). All the points in these passages seem to boil down to the claim that truth cannot be a property. The rhetorical question, 'May we not be dealing here with something which cannot be called a property in the ordinary sense at all?', is found at the end of these passages. Furthermore, Frege here repeats the indefinability argument he gives in 'Logic' (1897). As we have seen, the main point of this argument is that truth is a not property. Now, if it is Frege's aim to convince people of the point that truth is not a property, then he must not depend on truth being the True. If he were to maintain that truth is not a property because it is the True, nobody would buy into it; for it is a sloppy argument that truth is not a property because it is an object. Rather, Frege must establish that, whatever we may mean by 'true' or 'truth', it cannot be a property. If that is what Frege is doing in 'Thought', the fact that he does not mention truth-values in 'Thought' does not show that he denies that truth is the True.

Criticism 2. Truth must be something that can be predicated.

This criticism is grounded in the following passage from 'Thought':

We cannot recognize a property of a thing without at the same time finding the thought this thing has this property to be true. So with every property of a thing there is tied up a property of a thought, namely truth. (Frege 1918a: 328)

However, we should note that the fact that the truth-predication is ubiquitous is one of the reasons why Frege rhetorically asks: 'May we not be dealing with something which cannot be called a property in the ordinary sense at all?' (Frege 1918a 328) If so, we cannot comprehend Frege's comment 'with every property of a thing there is tied up a property of a thought [i.e., the property of truth]' at facevalue. Moreover, what Frege is pointing out by the ubiquity of truth-predication seems to be the identity between $\langle p\rangle$ and $\langle\langle p\rangle$ is true $\rangle$. We should recall that, from that point, Frege infers that truth cannot be a property. It is hence not warranted to infer from the previous passage that truth should be able to be predicated.

Criticism 3: Truth is indefinable while the True is definable.

Certainly, Frege stipulates that the True is the value range of the horizontal, that is, $\dot{\epsilon}(-\epsilon)$. However, it is not evident that Frege is really giving a definition of the True there. In general, it is very difficult to understand what is going on in $\S 10$ 
of Grundgesetze (Heck 2012. 51). As Greimann points out, Frege is dealing with the referential indeterminacy of value-range terms, which is left by Frege's initial stipulation about value-range terms that ' $\hat{\epsilon} \Phi(\epsilon)=\dot{\alpha} \Psi(\alpha)$ ' is coreferential with ' $\mathfrak{a}-\Phi(\mathfrak{a})=\Psi(\mathfrak{a})$ '. This stipulation gives us the basic law V: $(\dot{\epsilon} f(\epsilon)=\dot{\alpha} g(\alpha))=$ $(\mathfrak{a}-f(\mathfrak{a})=g(\mathfrak{a}))$. The problem is that this stipulation for the law $\mathrm{V}$ is not sufficient to decide whether an object, which is not given by a value-range term, is identical with a value-range. ${ }^{23}$ But the True and the False are not given by value-range terms. Hence,

... The question whether one of the truth-values is a value-range cannot possibly decided on the basis of ' $\dot{\epsilon} \Phi(\epsilon)=\dot{\alpha} \Psi(\alpha)$ ' having the same reference as ' $\mathfrak{a}-\Phi(\mathfrak{a})=\Psi(\mathfrak{a})^{\prime}$. (Frege 1893: 17)

Based on this point, Frege establishes that 'ironically enough' (Heck 2012 91), without contradicting our equating 'ée $\Phi(\epsilon)=\dot{\alpha} \Psi(\alpha)$ ' with ' $\mathfrak{a}-\Phi(\mathfrak{a})=$ $\Psi(\mathfrak{a})^{\prime}$, it is always possible to determine that an arbitrary value-range be the True and another arbitrary value-range be the False. (Frege 1893: 17)

Frege's 'definition' of the True comes right after this:

Let us therefore stipulate that $\dot{\epsilon}(-\epsilon)$ be the True and that $\dot{\epsilon}\left(\epsilon=\left(\tau^{\mathfrak{a}}-\mathfrak{a}=\right.\right.$ a) be the False. (Frege 1893: 17)

Frege's 'definition' of the True hence comes as a completely arbitrary stipulation. It is by no means clear that this stipulation, coming out of nowhere, is really intended to be a genuine definition of the True. ${ }^{24}$ It is possible that Frege makes this stipulation only for the sake of his argument that all the expressions of Begriffsschrift are referential. At the very least, it is controversial whether Frege takes this stipulation as a genuine definition of the True constituting a part of Begriffsschrift.

Textual evidence rather appears to justify that Frege distinguishes truth-values from value-ranges. He quickly stops talking about value-ranges after he realizes that his attempted solution to Russell's paradox is not successful. However, Frege still talks about truth-values after that. For instance, in '[Notes for Ludwig Darmstaedter]', he writes ,

23. This question sounds similar to the Caesar problem from Grundlagen (Frege 1884). Indeed, Frege's discussion around $\S 10$ is deeply related to the Caesar problem. See Chapter 3 of Heck (2012).

24. In Frege's logicism, numbers are defined as value-ranges. To justify these definitions, Frege provides a long discussion about traditional attempts to define numbers and a detailed analysis of number statements. This can be one reason why it is hard to believe that this one-line stipulation is intended to be a genuine, serious, definition of the True. According to Blanchette (2012), Frege did have quite a sophisticated conception of conceptual analysis and this stipulation is far from Frege's conception of conceptual analysis. 
All sentences that express a true thought have the same [reference] and all sentences that express a false thought have the same [reference] (the True and the False). (Frege 1919. 255)

At this point, Frege stops talking about value-ranges. But he is still talking about truth-values. If so, it seems, Frege distinguishes truth-values from value-ranges.

Even if the stipulation in Grundgesetze is intended by Frege to be a definition of the True, however, Greimann's objection fails to threaten the object reading. Given the exegesis of Frege's indefinability argument, what he really argues when he says that truth is indefinable is that truth cannot be a property and hence cannot be defined qua a property. To say that truth is indefinable qua a property is compatible with saying that truth is definable qua an object. Therefore, Frege's indefinability of truth does not go against the object reading in any event.

One might object that, presenting the indefinability argument in 'Thought', Frege does write,

Any other attempt to define truth also breaks down. (1918a: 327)

If this means that truth is not definable qua any kind of entity, the definability of the True shows that, for Frege, truth is not the True. But the above statement is immediately followed by this:

For in a definition certain characteristics would have to be specified. 1918a: 327)

Therefore, Frege is talking about definitions that ascribe characteristics to truth. As Künne 2008; 2013) notes, it is only a property that can have characteristics. ${ }^{25}$ The characteristic of a property $P$ is the property constitutive of $P$ that is specified in the definition of $P$. Thus, Frege is arguing here that a definition that ascribes characteristics to truth, that is, a definition that takes truth as a property, must fail. In other words, he is arguing that truth is indefinable qua a property.

Greimann's criticisms are not sufficient to refute the object reading of Frege's conception of truth. Also, the object reading provides a plausible understanding of Frege's remarks. Thus, the object reading is still arguably a tenable reading of Frege's conception of truth.

\section{References}

Baldwin, Thomas (1995). Three Puzzles in Frege's Theory of Truth. In Petr Kotatko and John Biro (Eds.), Frege: Sense and Reference One Hundred Years Later (1-14). Kluwer.

25. Instead of 'characteristic', Künne uses 'mark'. 
Blanchette, Patricia A. (2012). Frege's Conception of Logic. Oxford University Press. Burge, Tyler (1986). Frege on Truth. In Leila Haaparanta and Jaakko Hintikka (Eds.), Frege Synthesized (97-154). D. Reidel.

Carruthers, Peter (1981). Frege's Regress. Proceedings of the Aristotelian Society, $82,17-32$.

Dummett, Michael (1973). Frege: Philosophy of Language. Harvard University Press.

Frege, Gottlob (1879). Begriffsschrift, eine der arithmetischen nachgebildete Formel sprache des reinen Denkens. Louis Nebert. Translated as Conceptual Notation, a Formal Language of Pure Thought Modelled upon that of Arithmetic in Frege (1970). Frege, Gottlob (1884). Die Grundlagen der Arithmetik: eine logisch-mathematische Untersuchung überden Begriffder Zahl. W. Koebner. Translated as Frege (1950). The Foundations of Arithmetic: A Logico-Mathematical Enquiry into the Concept of Number (John L. Austin, Trans.). Northwestern University Press.

Frege, Gottlob (1891). Funktion und Begriff. Verlag Hermann Pohle. Translated as Function and Concept in Frege (1970).

Frege, Gottlob (1892a). Ausführungen über Sinn und Bedeutung. Unpublished manuscript. Translated as Comments on Sense and Reference in Frege (1979).

Frege, Gottlob (1892b). Über Begriff und Gegenstand. Vierteljahresschrift für wissenschaftliche Philosophie, 100, 192-205. Translated as On Concept and Object in Frege (1970).

Frege, Gottlob (1892c). Über Sinn und Bedeutung. Zeitschrift für Philosophie und philosophische Kritik, 100, 25-50. Translated as On Sense and Reference in Frege (1970).

Frege, Gottlob (1893). Grundgesetze der Arithmetik (Vol. I). Verlag Hermann Pohle. Translated as Frege (2013). Basic Laws of Arithmetic (Philip Ebert and Marcus Rossberg, Trans.). Oxford University Press.

Frege, Gottlob (1897). Logik. Unpublished manuscript. Translated as Logic in Frege (1979).

Frege, Gottlob (1906a). Einleitung in die Logik. Unpublished manuscript. Translated as Introduction to Logic in Frege (1979).

Frege, Gottlob (1906b). Über Schoenflies: Die logischen Paradoxien der Mengenlehre. Unpublished manuscript. Translated as On Schoenflies: Die logischen Paradoxien der Mengenlehre in Frege (1979).

Frege, Gottlob (1918a). Der Gedanke: Eine Logische Untersuchung. Beiträge zur Philosophie des deutschen Idealismus, I, 58-77. Translated as Thought in Frege (1997).

Frege, Gottlob (1918b). Die Verneinung: Eine Logische Untersuchung. Beiträge zur Philosophie des deutschen Idealismus, I, 143-157. Translated as Negation in Frege (1997).

Frege, Gottlob (1919). [Aufzeichnungen für Ludwig Darmstaedter]. Unpublished 
manuscript. Translated as [Notes for Ludwig Darmstaedter] in Frege (1979). Frege, Gottlob (1923). Logische Untersuchungen. Dritter Teil: Gedankengefüge. Beiträge zur Philosophie des deutschen Idealismus, III, 36-51. Translated as Frege (1963). Compound Thoughts (R. H. Stoothoff, Trans.). Mind, 72(285), 1-17.

Frege, Gottlob (1970). Philosophical Writings of Gottlob Frege. Peter Geach and Max Black (Eds.). Oxford University Press.

Frege, Gottlob (1979). Posthumous Writings. Hans Hermes, Friedrich Kambartel, and Friedrich Kaulbach (Eds.). The University of Chicago Press.

Frege, Gottlob (1997). The Frege Reader. Michael Beaney (Ed.). Blackwell.

Frege, Gottlob (2013). Basic Laws of Arithmetic (Phillip Ebert and Marcus Rossberg, Trans.). Oxford University Press.

Greimann, Dirk (2004). Frege's Puzzle About the Cognitive Function of Truth. Inquiry, 47(5), 425-442.

Greimann, Dirk (2007). Did Frege Really Consider Truth as an Object? Grazer Philosophische Studien, 75(1), 125-148.

Greimann, Dirk (2008). Does Frege Use a Truth-Predicate in His Justification of the Laws of Logic? A Comment on Weiner. Mind, 117(466), 403-425.

Greimann, Dirk (2014). Frege on Truth, Assertoric Force and the Essence of Logic. History and Philosophy of Logic, 35(3), 272-288.

Greimann, Dirk (2015). Frege Performative Argument against Truth Relativism. Journal for the History of Analytical Philosophy, 3(2), 1-17.

Grossmann, Reinhardt (1969). Reflections on Frege's Philosophy. Evanston: Northwestern University Press.

Heck, Richard Kimberly (2007). Frege and Semantics. Grazer Philosophische Studien, 75(1), 27-63.

Heck, Richard Kimberly (2012). Reading Frege's Grundgesetze. Oxford University Press.

Heck, William and William Lycan (1979). Frege's Horizontal. Canadian Journal of Philosophy, 9(3), 479-492.

Heck, Richard Kimberly and Robert May (2018). Truth in Frege. In Michael Glanzberg (Ed.), Oxford Handbook of Truth (193-218). Oxford University Press.

Kremer, Michael (2000). Judgment and Truth in Frege. Journal of the History of Philosophy, 38(4), 549-581.

Künne, Wolfgang (2003). Conceptions of Truth. Oxford University Press.

Künne, Wolfgang (2008). Frege on Truths, Truth and the True. Studia Philosophica Estonica, 1(1), 5-42.

Künne, Wolfgang (2013). Merely Entertaining a Thought, Judging and Asserting. In Mark Textor (Ed.), Judgement and Truth in Early Analytic Philosophy and Phenomenology (52-73). Palgrave.

Pagin, Peter (2001). Frege on Truth and Judgment. Organon F, 8(1), 1-13.

Perovic, Katarina (2017). Bradley's Regress. In Edward N. Zalta (Ed.), The 
Stanford Encyclopedia of Philosophy (Winter 2017 ed.). Retrieved from https: //plato.stanford.edu/entries/bradley-regress/

Ricketts, Thomas (1996). Logic and Truth in Frege. Proceedings of the Aristotelian Society, Supplementary Volumes, 70, 121-140.

Ricketts, Thomas (2007). Quantification, Sentences, and Truth-Values. Manuscrito, 30(2), 459-491.

Taschek, William (2008). Truth, Assertion, and the Horizontal: Frege on "the Essence of Logic". Mind, 117(466), 375-401.

Textor, Mark (2010). Frege on Judging as Acknowledging the Truth. Mind, 119(475), 615-655. 